\title{
Prediction of loblolly pine wood properties using transmittance near-infrared spectroscopy
}

\author{
Robert Sykes, Bailian Li, Gary Hodge, Barry Goldfarb, John Kadla, and \\ H.-m. Chang
}

\begin{abstract}
Near-infrared (NIR) spectroscopy is a rapid nondestructive technique that has been used to characterize chemical and physical properties of a wide range of materials. In this study, transmittance NIR spectra from thin wood wafers cut from increment cores were used to develop calibration models for the estimation of $\alpha$-cellulose content, average fiber length, fiber coarseness, and lignin content in the laboratory. Eleven-year-old trees from two sites were sampled using 12-mm increment cores. Earlywood and latewood of ring 3 and ring 8 from these samples were analyzed in the laboratory using microanalytical methods for $\alpha$-cellulose content, average fiber length, fiber coarseness, and lignin content. NIR calibrations and laboratory measurements based on one site were generally reliable, with coefficients of determination $\left(R^{2}\right)$ ranging from 0.54 to 0.88 for average fiber length and $\alpha$-cellulose content, respectively. Predicting ring 8 properties using ring 3 calibration equations showed potential for predicting $\alpha$-cellulose content and fiber coarseness, with $R^{2}$ values of approximately 0.60 , indicating the potential for early selection. Predicting the wood properties using the calibration equations from one site to predict another showed moderate success for $\alpha$-cellulose content $\left(R^{2}=\right.$ $0.64)$ and fiber coarseness $\left(R^{2}=0.63\right)$, but predictions for fiber length were relatively poor $\left(R^{2}=0.43\right)$. Prediction of lignin content using transmittance NIR spectroscopy was not as reliable in this study, partially because of low variation in lignin content in these wood samples and large errors in measuring lignin content in the laboratory.
\end{abstract}

Résumé : La spectroscopie dans le proche infrarouge (PIR) est une méthode rapide et non destructive qui a été utilisée pour caractériser les propriétés chimiques et physiques d'une vaste gamme de matériaux. Dans cette étude, les spectres de transmittance PIR de minces copeaux de bois prélevés sur des carottes ont été utilisés pour développer des modèles capables d'estimer le contenu en $\alpha$-cellulose, la longueur moyenne des fibres, la grosseur du grain et le contenu en lignine mesurés en laboratoire. Des arbres âgés de 11 ans ont été échantillonnés dans deux stations en prélevant des carottes de $12 \mathrm{~mm}$. Le bois initial et le bois final des cernes trois et huit de ces échantillons ont été analysés en laboratoire à l'aide de techniques micro-analytiques pour déterminer le contenu en $\alpha$-cellulose, la longueur moyenne des fibres, la grosseur du grain et la lignine. L'étalonnage PIR avec les mesures en laboratoire basées sur les échantillons d'une station était généralement fiable avec des coefficients de détermination $\left(R^{2}\right)$ variant respectivement de 0,54 à 0,88 pour la longueur moyenne des fibres et le contenu en $\alpha$-cellulose. Il était possible de prédire les propriétés du cerne huit à partir des équations du cerne trois dans le cas du contenu en $\alpha$-cellulose et de la grosseur du grain avec des valeurs de $R^{2}$ d'environ 0,60 , ce qui démontre un certain potentiel pour la sélection précoce. Les équations propres à une station permettaient de prédire les propriétés du bois d'une autre station avec un certain succès pour le contenu en $\alpha$-cellulose $\left(R^{2}=0,64\right)$ et la grosseur du grain $\left(R^{2}=0,63\right)$ mais les prédictions pour la longueur des fibres étaient relativement médiocres $\left(R^{2}=0,43\right)$. La prédiction du contenu en lignine à l'aide la transmittance PIR n'était pas fiable dans cette étude à cause de la faible variation dans le contenu en lignine des échantillons et les erreurs importantes dans les mesures de la lignine effectuées en laboratoire.

[Traduit par la Rédaction]

\section{Introduction}

Improvement of growth, stem straightness, disease resistance, and specific gravity has been the primary focus of tree breeding, owing to their economic importance and ease of measurement (Zobel and Talbert 1984). Large genetic gains in growth, stem form, and rust infection from two breeding cycles have been documented for loblolly pine (Pinus taeda L.) (Li et al. 1999), but relatively little work has been done in this species on improving wood properties, except specific gravity. Chemical and morphological wood properties, including $\alpha$-cellulose content, average fiber length, and fiber coarseness (hereinafter referred to as fiber length and coarseness, respectively) can have major impacts on pulp

Received 16 December 2004. Accepted 6 July 2005. Published on the NRC Research Press Web site at http://cjfr.nrc.ca on 1 November 2005.

R. Sykes, B. Li, ${ }^{1}$ G. Hodge, and B. Goldfarb. Department of Forestry, College of Natural Resources, Box 8002, North Carolina State University, Raleigh, NC 27695, USA.

J. Kadla and H.-m. Chang. Department of Wood and Paper Sciences, College of Natural Resources, North Carolina State University, Raleigh, NC 27695, USA.

${ }^{1}$ Corresponding author (e-mail: Bailian_li@ncsu.edu). 
and paper products (Zobel and Talbert 1984; Kerekes and Schell 1995; Kube and Raymond 2002). The $\alpha$-cellulose content is highly correlated with pulp yield (Kube and Raymond 2002). Increasing the $\alpha$-cellulose content in wood would reduce pulping costs and increase the efficiency of pulp and paper mills (Zobel and Talbert 1984). Fiber length also plays an important role in the pulp and paper industry. Long fibers yield paper with greater tensile and tear strength for products such as cardboard and paper bags (Myers 2001). Short fibers are preferred for products such as fine printing paper, where surface smoothness and resistance to ink bleeding are important. Coarseness is the total mass of a sample of fibers divided by the total length of all fibers. Coarser fibers tend to have large lumens, therefore it is difficult to separate the effects of lumen size and wall thickness (Kerekes and Schell 1995). Lower coarseness values result in easier fiber collapse, allowing better bonding of fibers and the formation of dense paper with a smooth surface. Wood with higher coarseness values yields pulp and paper products with higher bulk, which is beneficial for products requiring higher absorbance and (or) greater stiffness to bending.

One of the limitations in genetic improvement of wood is the difficulty of measuring these traits on many trees and in progeny trials. To obtain an accurate assessment of a breeding population, analyses of many trees are required in progeny tests. Traditional laboratory methods for measuring the chemical properties of wood are expensive and time-consuming. Recently, a microanalytical technique has been developed to screen the chemical properties of progeny-test trees using a small sample of wood (Yokoyama et al. 2002). Using this method, genetic variation in a number of properties was identified in a large loblolly pine progeny test (Sykes et al. 2003). Although this analysis is more rapid than previous chemical analyses, it is still costly and time-consuming, particularly for a large progeny test. Therefore, a more rapid and inexpensive screening technique is needed to allow wood properties to be incorporated into breeding programs.

Near-infrared (NIR) spectroscopy is a rapid, nondestructive technique that has been used to characterize diverse substances such as pharmaceuticals and wood. NIR spectroscopy has successfully been used to characterize wood and fiber properties (Wright et al. 1990; Michell 1995; Raymond et al. 2001b; Schimleck and Evans 2003; Kelly et al. 2004). Most NIR studies use reflectance NIR spectroscopy to predict the wood properties of wood meal or solid wood (Raymond et al. 2001a; Jones et al. 2005), but reflectance measurements suffer from several limitations, the most serious being the small penetration depth $(1-4 \mathrm{~mm})$ into the sample. Thus, when using reflectance measurements the uniformity of particle size becomes very important (Schimleck et al. 2001, 2003; Schimleck and Evans 2002). The milled wood must be screened to remove the larger particles to ensure uniformity of the sample. For nonhomogeneous samples such as wood, this limited penetration can lead to variable results and a strong dependence on sample size and preparation technique. Furthermore, because a large amount of wood meal is typically used to represent the sample of interest, independent measurements of individual rings for earlywood and latewood are not possible.

In contrast, transmittance techniques can allow full penetration of the sample (depending on thickness), are less sen- sitive to particle-size effects, and permit analysis of smaller wood samples. Yeh et al. (2004) recently reported the use of transmittance NIR spectroscopy to study lignin content in earlywood and latewood from 12-mm increment wood cores. In this paper, we examine the use of transmittance NIR spectroscopy to measure $\alpha$-cellulose content, fiber length, coarseness, and lignin content of juvenile wood and transition wood in loblolly pine. Using 12-mm increment cores of 11-year-old loblolly pine trees, earlywood and latewood of juvenile and transition rings were evaluated by transmittance NIR spectroscopy, and their relationships with laboratory data were tested to determine the usefulness of this technique for predicting wood properties in breeding programs.

\section{Materials and methods}

\section{Wood-sample collection}

Samples of wood from loblolly pine trees from tests of field-grown progeny were collected and processed as described previously (Sykes et al. 2003). Briefly, 14 full-sib families generated by a six-parent half-diallel mating design were tested in the Piedmont of South Carolina. A randomized complete-block design with six replications was used in the field. Each full-sib family was laid out in a six-tree row plot in each replication. Wood-core samples from 11-yearold trees were collected from two sites in South Carolina. Increment cores $(12 \mathrm{~mm})$ were taken from each tree at breast height (approximately $1.30 \mathrm{~m}$ ) using generator-powered drills. Wood cores having visible limbs, curves, resin pockets, compression wood, or rust infections were avoided. The samples were placed in plastic storage bags, labeled, and kept in coolers to retain moisture during material collection and transportation. In this study, 40 trees from two full-sib families were sampled on site A and another 30 trees from three full-sib families were sampled on site B. The two sites were within 15 miles of each other in South Carolina. Trees on site A, which was located in a river bottom, had faster growth and greater uniformity than those on site B, which was established in the upland Piedmont.

\section{Measurements of wood properties}

The bark and cambium were removed from the wood cores and the cores were split at the pith into two halves. Thin wafers $(200 \mu \mathrm{m})$ were cut with a microtome from ring 3 earlywood (3E), ring 3 latewood (3L), ring 8 earlywood (8E), and ring 8 latewood ( $8 \mathrm{~L})$ from each wood core. These rings were chosen to represent the juvenile (ring 3) and transition (ring 8) sections of the tree (Sykes et al. 2003). With 70 increment cores and four ring segments per core, there were approximately 280 samples. Each ring sample consisted of wood wafers that weighed at least $300 \mathrm{mg}$. Sixteen wood wafers were randomly taken from each ring and wood type, measured using NIR spectroscopy, and then saved for cellulose determination. The wafers were pressed between glass microscope slides under small weights to ensure flatness during the drying process. Wafers with noticeable variation in thickness were discarded. Prior to NIR analysis, each sample was placed in a vacuum desiccator with $\mathrm{P}_{2} \mathrm{O}_{5}$ for 2 days to remove moisture. 
Table 1. Descriptive statistics for wood properties obtained from wet-chemistry data for site A, site B, and the two sites combined.

\begin{tabular}{|c|c|c|c|c|}
\hline \multirow[b]{2}{*}{ Data set } & \multicolumn{4}{|c|}{ Wood property } \\
\hline & $\mathrm{ACY}(\%)$ & $\mathrm{COA}(\mathrm{mg} / \mathrm{mm})$ & FLW (mm) & LIG $(\%)$ \\
\hline \multicolumn{5}{|l|}{ Among wood samples } \\
\hline \multicolumn{5}{|l|}{ Combined sites $(n=240)$} \\
\hline Min. & 35.6 & 0.223 & 0.491 & 24.1 \\
\hline Max. & 55.2 & 0.699 & 3.04 & 32.63 \\
\hline Mean & 44.7 & 0.369 & 1.598 & 29.24 \\
\hline Standard deviation & 4.3 & 0.101 & 0.531 & 1.44 \\
\hline \multicolumn{5}{|l|}{ Site A $(n=128)$} \\
\hline Min. & 35.6 & 0.223 & 0.85 & 24.1 \\
\hline Max. & 54.3 & 0.547 & 3.04 & 32.63 \\
\hline Mean & 43.3 & 0.337 & 1.751 & 29.09 \\
\hline Standard deviation & 4.5 & 0.071 & 0.494 & 1.45 \\
\hline \multicolumn{5}{|l|}{ Site B $(n=112)$} \\
\hline Min. & 36.6 & 0.242 & 0.491 & 26.5 \\
\hline Max. & 55.2 & 0.699 & 2.66 & 32.37 \\
\hline Mean & 46.3 & 0.406 & 1.423 & 29.41 \\
\hline Standard deviation & 3.6 & 0.116 & 0.521 & 1.42 \\
\hline \multicolumn{5}{|c|}{ Among repeated measures of the same wood samples } \\
\hline Laboratory standard error & 1.805 & 0.011 & 0.034 & 0.638 \\
\hline
\end{tabular}

Wood wafers were analyzed using a NIR spectrometer (Foss Model 6500). A single wafer was scanned to measure the amount of NIR light (600-1900 nm) transmitted through the sample. To ensure uniformity, fiber orientation was kept constant for all samples, and samples were analyzed in a dry condition. The 16 spectra for each ring and wood type were averaged to create one spectrum, which was used for the calibration equations, with $\alpha$-cellulose content, fiber length, coarseness, and lignin content estimated in the laboratory (Sykes et al. 2003).

These wood wafers were used for chemical analysis in the laboratory. Using a microanalytical technique developed by Yokoyama et al. (2002), several wood properties, including lignin content, $\alpha$-cellulose content, fiber length, and coarseness, were determined for each ring (rings 3 and 8) and for the wood types earlywood and latewood. Descriptive statistics for the wood properties were calculated and are reported in Table 1. Laboratory standard errors were calculated by repeating measurements of $\alpha$-cellulose content, fiber length, and coarseness three times and lignin content twice, for approximately 50 samples.

\section{Calibration of NIR-spectroscopy data}

The NIR spectrometer produced spectra from 600 to $1900 \mathrm{~nm}$ in 2-nm increments, which were converted to the second derivative to remove the baseline offset and sloping effects that are common in NIR spectra (Thosar et al. 2001). The second-derivative data showed noise at both ends of each spectrum (Fig. 1), therefore calibration equations were based on a reduced spectrum. Michell and Schimleck (1996) report that one of the major bands for prediction of $\alpha$-cellulose content occurred at $1477 \mathrm{~nm}$, whereas a major band for prediction of lignin content occurred at $1668 \mathrm{~nm}$. Following this report, calibrations for coarseness, fiber length, and $\alpha$-cellulose content were based on wavelengths from 800 to $1600 \mathrm{~nm}$ (Fig. 1), and calibrations for lignin content were based on wavelengths from 800 to $1750 \mathrm{~nm}$.

The coefficient of determination $\left(R^{2}\right)$ was estimated between the laboratory chemistry data and the values predicted by NIR spectroscopy using partial least squares regression models. The number of factors to be used in each calibration model was chosen by determining when the mean square error of cross-validation reached a minimum and started to plateau (Miller 1989). In addition to $R^{2}$, the standard error of calibration (SEC) was used to evaluate how precisely the regression line fit the data:

$$
\mathrm{SEC}=\sqrt{\frac{\sum_{i=1}^{\mathrm{NC}}\left(\hat{y}_{i}-y_{i}\right)^{2}}{\mathrm{NC}-k-1}}
$$

where $\hat{y}_{i}$ is the value of the constituent for validation sample $i$ estimated by the calibration model; $y_{i}$ is the known value of the constituent of sample $i$; NC is the number of samples used in the development of the calibration equation; and $k$ is the number of factors used to develop the model (Workman 1992; Raymond and Schimleck 2002). SEC is the standard deviation of the residuals that is due to the difference between the wet-chemistry data from the laboratory and the values predicted by NIR spectroscopy within the calibration set (Mark and Workman 1991; Bailleres et al. 2002). The standard error of cross-validation (SECV) was also determined to measure how well the calculated equations predicted the samples that were not used to create the calibration set (FOSS NIRSystems 2001). The SECV is given by 
Fig. 1. Examples of second-derivative NIR spectra for ring 3 earlywood (3E), ring 3 latewood (3L), ring 8 earlywood (8E), and ring 8 latewood (8L) for one increment core. Cutoff points used for $\alpha$-cellulose content (ACY), fiber coarseness (COA), and average fiber length (FLW) were wavelengths $800-1600 \mathrm{~nm}$, whereas cutoff points for lignin content were wavelengths $800-1750 \mathrm{~nm}$.

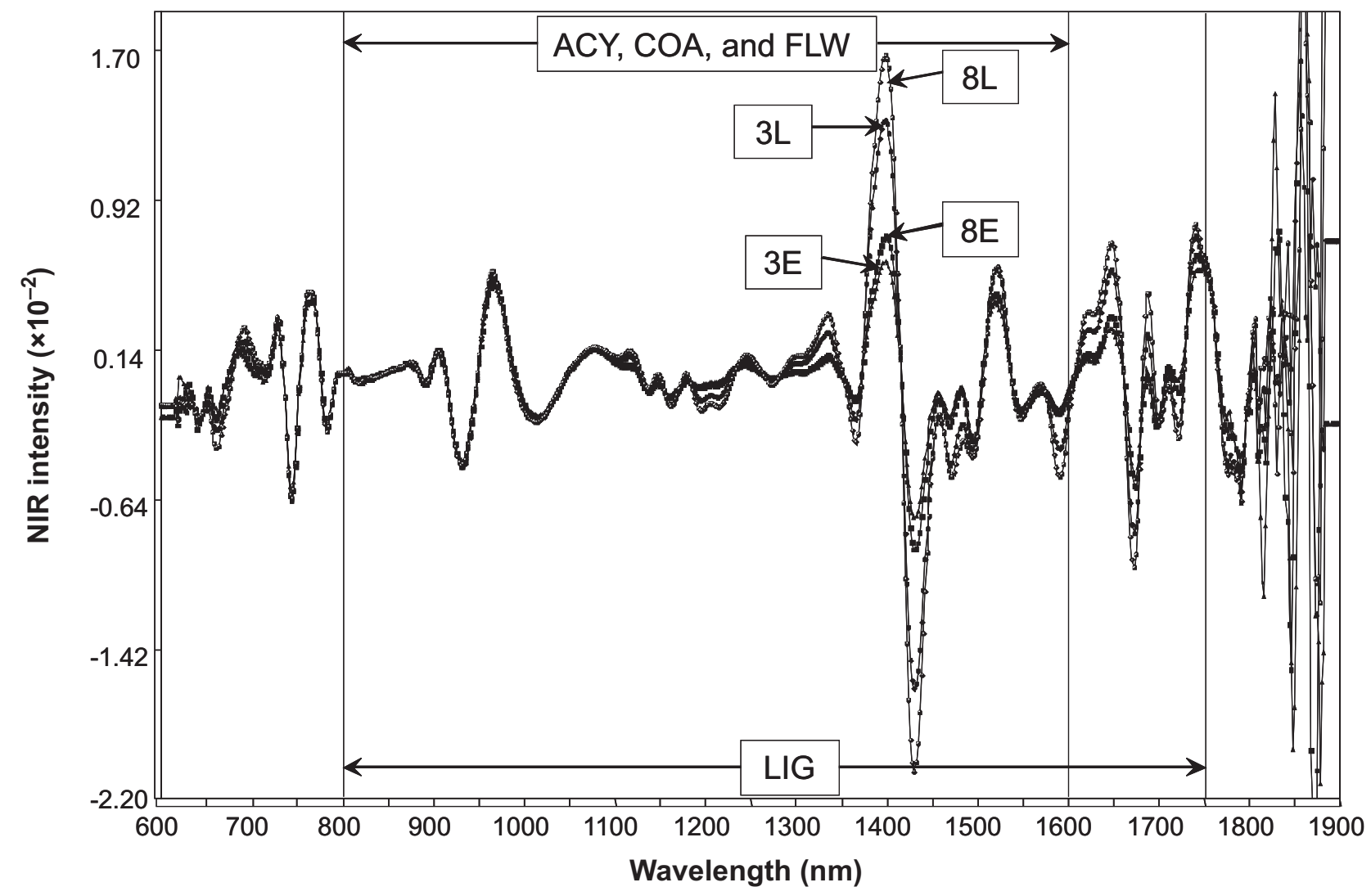

$$
\operatorname{SECV}_{j}=\sqrt{\frac{\sum_{i=1}^{n}\left(\hat{x}_{i j}-x_{i}\right)^{2}}{n}}
$$

where $j$ is the number of factors used to develop the calibration equations; $x_{i}$ is the known value of the constituent for sample $I ; \hat{x}_{i j}$ is the value of the constituent for sample $i$ predicted by the model (excluding sample $i$ ) developed with $j$ factors; and $n$ is the number of samples (Schimleck et al. 1999). Cross-validation involves dividing the calibration set randomly into four equal-sized segments. One segment is excluded and the other three segments are used to develop a partial least squares model. This model is then checked to determine how well it fits the samples in the excluded set. This process is repeated four times to validate all the samples and provide an estimate of SECV (Schimleck et al. 1999). A prediction function was used to predict a set of unknown data using the previously established calibration equations to produce the standard error of prediction (SEP) as well as the $R^{2}$ value for the prediction set. The SEP is given by

$$
\mathrm{SEP}=\sqrt{\frac{\sum_{i=1}^{\mathrm{NP}}\left(\hat{y}_{i}-y_{i}\right)^{2}}{\mathrm{NP}-1}}
$$

where $\hat{y}_{i}$ is the value of the constituent for prediction sample $i$ predicted by the calibration model; $y_{i}$ is the known value of the constituent of sample $i$; and NP is the number of samples used in the prediction set (Workman 1992).

Calibration models for each data set (combined data, individual site data, individual ring data, and earlywood and latewood data) were developed using $75 \%$ of the samples, while the remaining $25 \%$ of samples were used for validation of the models. Each ring sample (3E, 3L, 8E, and 8L) was analyzed individually to test whether earlywood and latewood produced different results. The calibration equations from site $\mathrm{A}$ with a higher $R^{2}$ value were used to predict wood properties on site B. Ring 3 equations were used to predict ring 8 data for examining how well the equations can be extrapolated on relatively different data sets. Similarly, calibration equations based on site A were used to predict data collected from site B.

To minimize the variation in thickness of wood wafers and variation within the ring, several mathematical options were tested. The partial least squares analysis was completed by using the multiplicative scatter correction, whereas the second derivative was used to standardize the data and eliminate some of the variation in NIR intensity due to differences in thickness. Using multiplicative scatter correction, the light scattering or change in path length for each sample is estimated relative to that of an ideal sample, effectively reducing spectral noise (Næs et al. 1990). Although several other regression options 
Table 2. Linear regression models fitted to predict wood properties measured using wet chemistry from nearinfrared spectra for site A, site B, and the two sites combined for latewood (3L and $8 \mathrm{~L})$, earlywood (3E and $8 \mathrm{E})$, ring $3(3 \mathrm{E}$ and $3 \mathrm{~L})$, ring $8(8 \mathrm{E}$ and $8 \mathrm{~L})$, and for combined data $(3 \mathrm{E}, 3 \mathrm{~L}, 8 \mathrm{E}$, and $8 \mathrm{~L})$.

\begin{tabular}{|c|c|c|c|c|c|c|c|c|c|c|}
\hline \multirow[b]{2}{*}{ Data set } & \multirow[b]{2}{*}{$n$} & \multicolumn{3}{|c|}{$\mathrm{ACY}(\%)$} & \multicolumn{3}{|c|}{$\mathrm{COA}(\mathrm{mg} / \mathrm{mm})$} & \multicolumn{3}{|c|}{ FLW (mm) } \\
\hline & & $R 2$ & SEC & SECV & $R^{2}$ & SEC & SECV & $R^{2}$ & SEC & SECV \\
\hline \multicolumn{11}{|l|}{ Site A } \\
\hline Latewood & 70 & 0.88 & 1.882 & 2.322 & 0.61 & 0.053 & 0.037 & 0.71 & 0.231 & 0.345 \\
\hline Earlywood & 65 & 0.73 & 1.545 & 1.305 & 0.54 & 0.022 & 0.026 & 0.67 & 0.255 & 0.275 \\
\hline Ring 3 & 70 & 0.68 & 1.617 & 1.715 & 0.74 & 0.029 & 0.038 & 0.60 & 0.203 & 0.222 \\
\hline Ring 8 & 65 & 0.83 & 1.811 & 2.074 & 0.74 & 0.042 & 0.046 & 0.68 & 0.283 & 0.285 \\
\hline Combined & 135 & 0.86 & 1.931 & 2.212 & 0.73 & 0.044 & 0.045 & 0.72 & 0.309 & 0.354 \\
\hline \multicolumn{11}{|l|}{ Site B } \\
\hline Latewood & 55 & 0.63 & 2.037 & 3.099 & 0.24 & 0.084 & 0.079 & 0.42 & 0.363 & 0.278 \\
\hline Earlywood & 60 & 0.70 & 1.435 & 1.692 & 0.47 & 0.054 & 0.064 & 0.48 & 0.282 & 0.203 \\
\hline Ring 3 & 55 & 0.51 & 2.189 & 1.853 & 0.41 & 0.076 & 0.098 & 0.54 & 0.235 & 0.292 \\
\hline Ring 8 & 60 & 0.46 & 2.606 & 3.100 & 0.35 & 0.098 & 0.055 & 0.55 & 0.448 & 0.475 \\
\hline Combined & 115 & 0.73 & 1.992 & 2.135 & 0.63 & 0.067 & 0.079 & 0.55 & 0.297 & 0.372 \\
\hline \multicolumn{11}{|l|}{ Combined sites } \\
\hline Latewood & 120 & 0.63 & 2.718 & 2.882 & 0.36 & 0.076 & 0.068 & 0.38 & 0.390 & 0.453 \\
\hline Earlywood & 120 & 0.60 & 2.341 & 1.890 & 0.39 & 0.041 & 0.058 & 0.27 & 0.367 & 0.350 \\
\hline Ring 3 & 140 & 0.57 & 2.162 & 2.232 & 0.44 & 0.056 & 0.053 & 0.18 & 0.266 & 0.303 \\
\hline Ring 8 & 110 & 0.56 & 2.510 & 3.400 & 0.52 & 0.070 & 0.089 & 0.27 & 0.505 & 0.560 \\
\hline Combined & 250 & 0.75 & 2.417 & 2.134 & 0.64 & 0.059 & 0.066 & 0.43 & 0.387 & 0.392 \\
\hline
\end{tabular}

Note: The number of factors for these calibration equations ranged from three to six. $R^{2}$ is the coefficient of determination, SEC is the standard error of the calibration, SECV is the standard error for cross-validation, ACY is $\alpha$-cellulose content, COA is fiber coarseness, and FLW is average fiber length. Sample sizes $(n)$ are approximate because some values are missing.

Fig. 2. Calibration data for combined sites to predict $\alpha$-cellulose content (ACY). The standard error of calibration (SEC), standard error of cross-validation (SECV), and $R^{2}$ value are given $(n \approx 180)$.

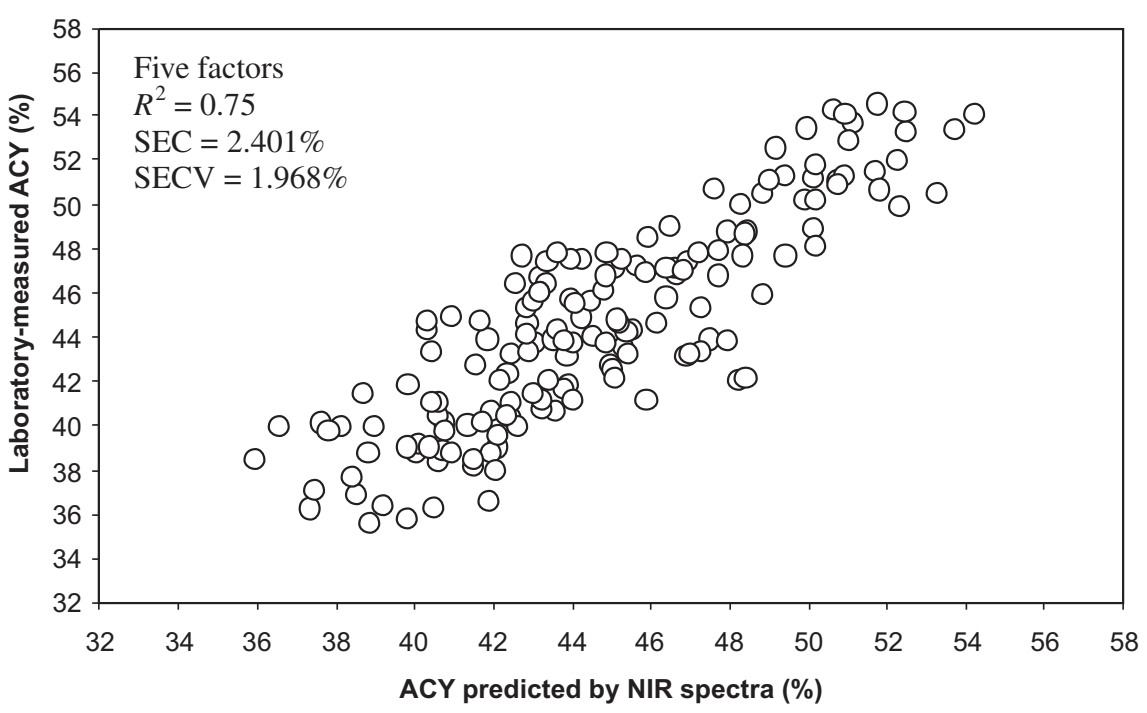

were examined, these did not improve the calibration equations and so are not reported.

\section{Results}

\section{NIR-spectroscopy calibrations}

The fitted calibration models of $\alpha$-cellulose content, coarseness, and fiber length with NIR spectra showed linear relationships between NIR-spectroscopy and wet-chemistry data (Table 2). For the combined site analysis, regression models based on the whole data set with samples $3 \mathrm{E}, 3 \mathrm{~L}, 8 \mathrm{E}$, and
$8 \mathrm{~L}$ resulted in higher $R^{2}$ values than subsets broken out by earlywood-latewood or ring 3 - ring 8 (Table 2 ). The range of $R^{2}$ values for $\alpha$-cellulose content was between 0.56 and 0.63 for the two wood types and the two rings, whereas the coefficient increased to 0.75 for the whole-core data set (Fig. 2). Results from NIR spectroscopy explained the lower percentages of variation in laboratory measurements of coarseness $\left(R^{2}=0.64\right)$ and fiber length $\left(R^{2}=0.43\right)$.

The calibration models for lignin content had low $R^{2}$ values, that is, a low association $\left(R^{2}=0.16\right)$ of laboratory data for site B with the NIR-spectroscopy predictions (Fig. 3), and 
Fig. 3. Calibration data for individual sites used to predict lignin content (LIG) using NIR spectra. The standard error of calibration (SEC), standard error of cross-validation (SECV), and $R^{2}$ value for each model are given $(n \approx 120$ and $n \approx 110$, respectively).
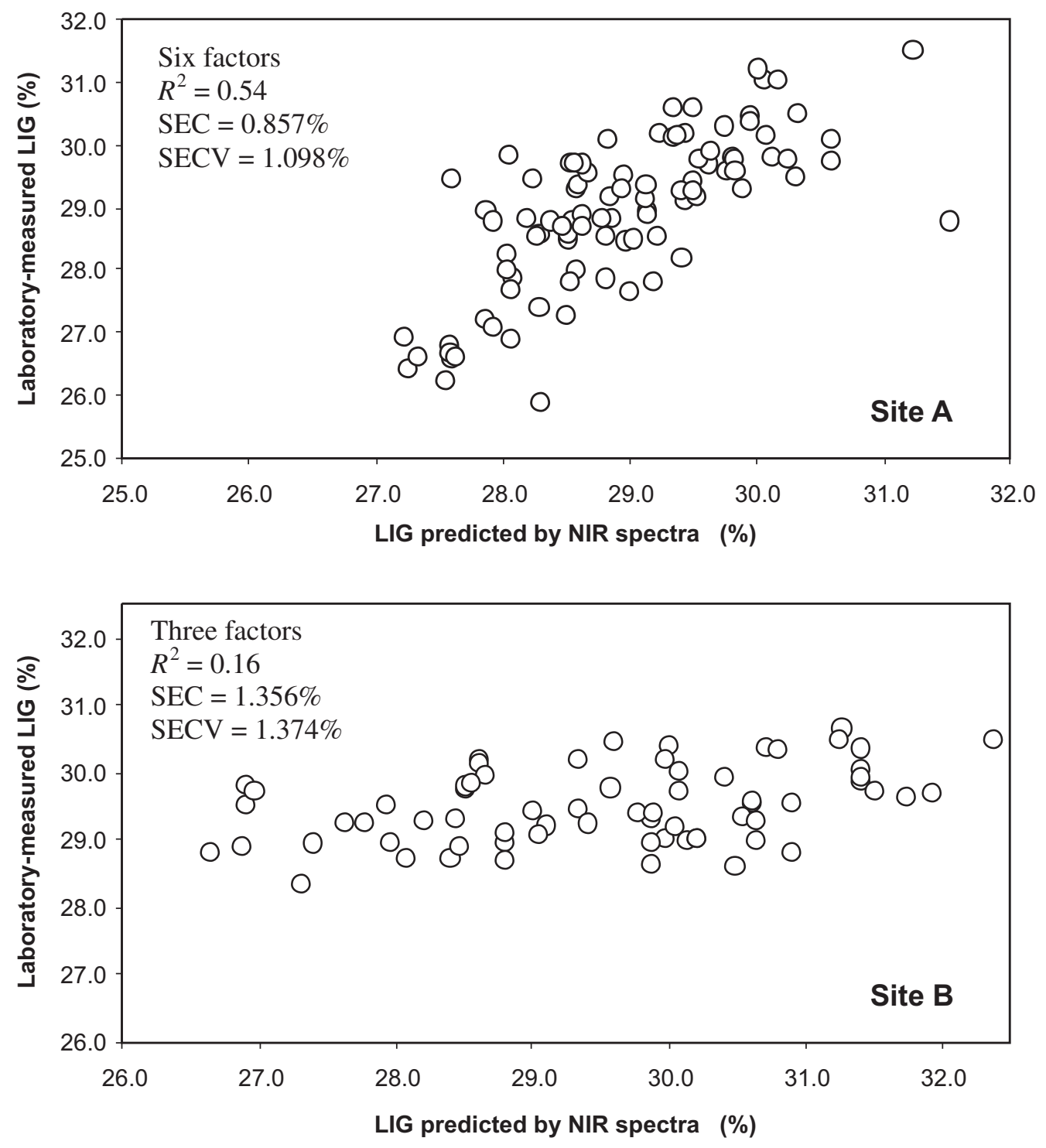

a low $R^{2}$ value $\left(R^{2}=0.37\right)$ with the complete data. Owing to the poor association of lignin content with NIR spectra on site $\mathrm{B}$, lignin content was not included in further analysis.

\section{NIR-spectroscopy calibrations by site}

Regression models based on site-A data showed higher $R^{2}$ values than those based on site-B data (Table 2). Relationships between the NIR-spectroscopy data and laboratory $\alpha$ cellulose contents were strongest for all the individual data sets and $R^{2}$ values ranged from 0.68 to 0.88 . Relationships between NIR-spectroscopy data and laboratory measurements for coarseness and fiber length were moderately strong for site A. The latewood and ring 8 data sets yielded the highest $R^{2}$ values, with slightly higher standard errors than the earlywood and ring 3 data sets on site A.

Regression models based on site-B data showed smaller $R^{2}$ values for all traits. The best calibration equation for $\alpha$ cellulose content had an $R^{2}$ value of 0.70 for the earlywood data on site B compared with 0.73 for site A (Table 2). In general, all standard errors for site B were higher than those for site A. Standard errors (SEC and SECV) for coarseness on site B were approximately twice those reported from site A. Similarly, standard errors for fiber length on site B were generally 1.5 times higher than those from site A. When all ring measurements were combined into one data set $(3 \mathrm{E}, 3 \mathrm{~L}$, $8 \mathrm{E}$, and $8 \mathrm{~L}$ ), calibrations resulted in stronger relationships for both sites, with $R^{2}$ values ranging from 0.72 to 0.86 on site $\mathrm{A}$ and from 0.55 to 0.73 on site B (Table 2).

\section{Predictions of NIR spectra between sites}

Whole-core calibration equations based on site A resulted in higher $R^{2}$ values and were used to predict the wood properties of the trees on site B. Using the calibration equations for $\alpha$-cellulose content and coarseness for site A to predict the NIR spectra that would be obtained from the site-B data yielded $R^{2}$ values of 0.64 and 0.63 (Fig. 4) compared with 0.73 and 0.63 for the site-B equations, respectively. The SEP for $\alpha$-cellulose content was approximately 1.5 times greater 
Fig. 4. Comparison of wood properties predicted using NIRspectroscopy calibration models from site A and laboratory measurements for samples from site B for $\alpha$-cellulose content (ACY), fiber coarseness (COA), and average fiber length (FLW). The standard error of prediction (SEP) and $R^{2}$ value for each model are given $(n=99)$.
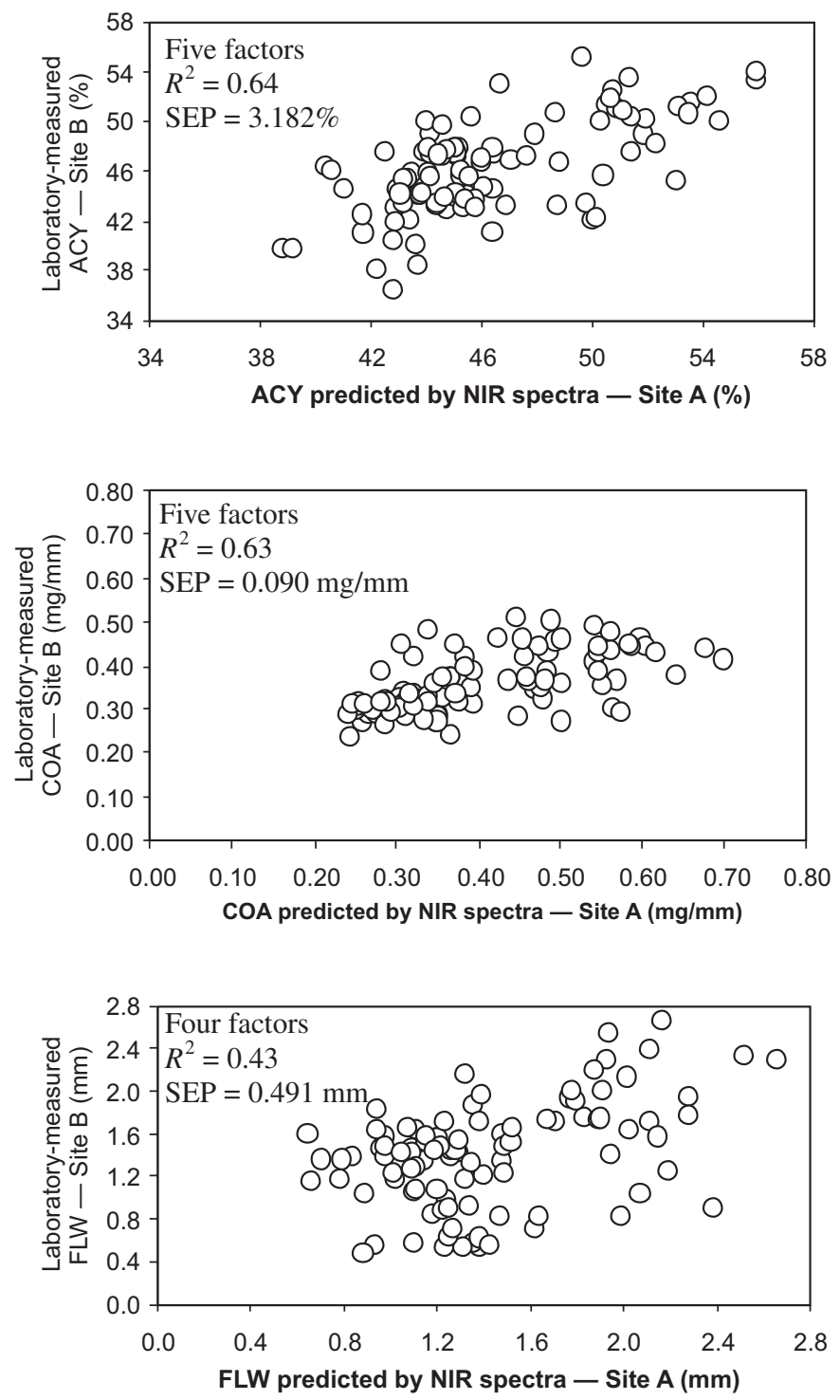

than the SEC found on site A, and the SEP of coarseness was twice the SEC (Table 2). Fiber length on site B was not well predicted from that on site $\mathrm{A}$, with a low $R^{2}$ value of 0.43 and a SEP that was nearly twice the SEC from site A.

Ring 3 calibration equations were used to predict the values for ring 8 . The predictions of $\alpha$-cellulose content yielded a positive relationship, with $R^{2}=0.60$ and a SEP of $3.53 \%$ (Fig. 5). Ring 3 prediction equations for coarseness of ring 8 resulted in a higher $R^{2}$ value (0.68) than using the ring 8 data independently $\left(R^{2}=0.52\right)$ with a SEP of 0.08 (Table 2$)$. A noticeable separation of earlywood and latewood was apparent in the coarseness distribution (Fig. 5). Latewood coarseness values were higher than those for earlywood, and separate into clusters in the graph. Fiber length predictions were not made, owing to the lower $R^{2}$ values.

\section{Discussion}

NIR transmittance provided relatively reliable calibrations for predicting $\alpha$-cellulose content in juvenile loblolly pine (Figs. 2, 5). The standard errors of calibration and prediction ranged from $1.43 \%$ to $3.55 \%$, depending on the data set that was used (Table 2, Fig. 5). The standard errors for $\alpha$-cellulose content were higher, with slightly lower $R^{2}$ values than those reported by Raymond and Schimleck (2002) using Eucalyptus globulus and Schimleck et al. (2004) using Eucalyptus nitens. Different laboratory methods for determining $\alpha$-cellulose values may lead to the higher errors in this study. Another difference was that the wood samples $(3 \mathrm{E}, 3 \mathrm{~L}, 8 \mathrm{E}$, and $8 \mathrm{~L}$ ) were maintained separately for NIR-spectroscopy analysis, whereas in other studies ground wood meal was used for $\alpha$ cellulose determination.

Reliable $\alpha$-cellulose content determination is important to the pulp and paper industry because $\alpha$-cellulose content is highly correlated with pulp yield (duPlooy 1980; Wright et al. 1990; Kube and Wallis et al. 1996a, 1996b; Schimleck and Michell 1998; Raymond 2002). If tree breeders can use NIR spectroscopy to rapidly and cost-effectively screen progeny tests to select trees with high $\alpha$-cellulose content, selected trees can be bred to improve pulp yields in plantations. Because a relatively high degree of genetic control was found in a population of juvenile loblolly pine (heritability ranged from 0.38 to 0.55 for juvenile and transition wood; Sykes et al. 2003), the $\alpha$-cellulose content could be improved by means of a breeding program using NIR spectroscopy for rapid screening and selection.

Fiber length calibrations varied in $R^{2}$ value from 0.40 on site B to 0.70 on site A (Table 2). The results suggest that environmental factors such as site differences may affect fiber length more than the other two traits. This was evident when data from both sites were used to create calibration equations. Correlations based on the whole-core data set were lower than those from individual sites and the corresponding SEC was higher (Table 2).

NIR spectroscopy is used mainly to measure overtone and combination bands of the fundamental stretching vibrations of $\mathrm{O}-\mathrm{H}, \mathrm{N}-\mathrm{H}$, and $\mathrm{C}-\mathrm{H}$ functional groups that contain chemical and physical information about a sample (Barton 1989). In this study, however, two physical properties of wood, coarseness and fiber length, were predicted moderately well using transmittance NIR spectroscopy. This may be due to their genetic correlations with $\alpha$-cellulose content: $r_{\mathrm{g}}=0.37$ and $r_{\mathrm{g}}=0.40$ for fiber length and coarseness, respectively (Sykes et al. 2003). Phenotypic correlations between $\alpha$-cellulose content and fiber length $\left(r_{\mathrm{p}}=0.52\right)$ and coarseness $\left(r_{\mathrm{p}}=\right.$ $0.33)$ were similar. The predictability of coarseness and fiber length may be due to pleiotropic effects, in which the same genes affect multiple traits simultaneously. Although calibration equations for fiber length and coarseness had lower $R^{2}$ values than those for $\alpha$-cellulose content, there were moderate associations that may be useful for using NIR spectra in predicting coarseness and fiber length.

The poor lignin-content calibration in this study may be due to the high laboratory standard error (Table 1). The site difference in the calibration equations may be due to environmental effects at these two sites and the high laboratory standard error. Yeh et al. (2004) used transmittance NIR spectroscopy to predict the lignin content of 12-mm wood 
Fig. 5. Comparison of wood properties predicted using NIR-spectroscopy calibration models from juvenile wood (ring 3) and laboratory measurements for samples from transition wood (ring 8) for $\alpha$-cellulose content (ACY) and fiber coarseness (COA). The standard error of prediction (SEP) and $R^{2}$ value for each model are given $(n=103)$.
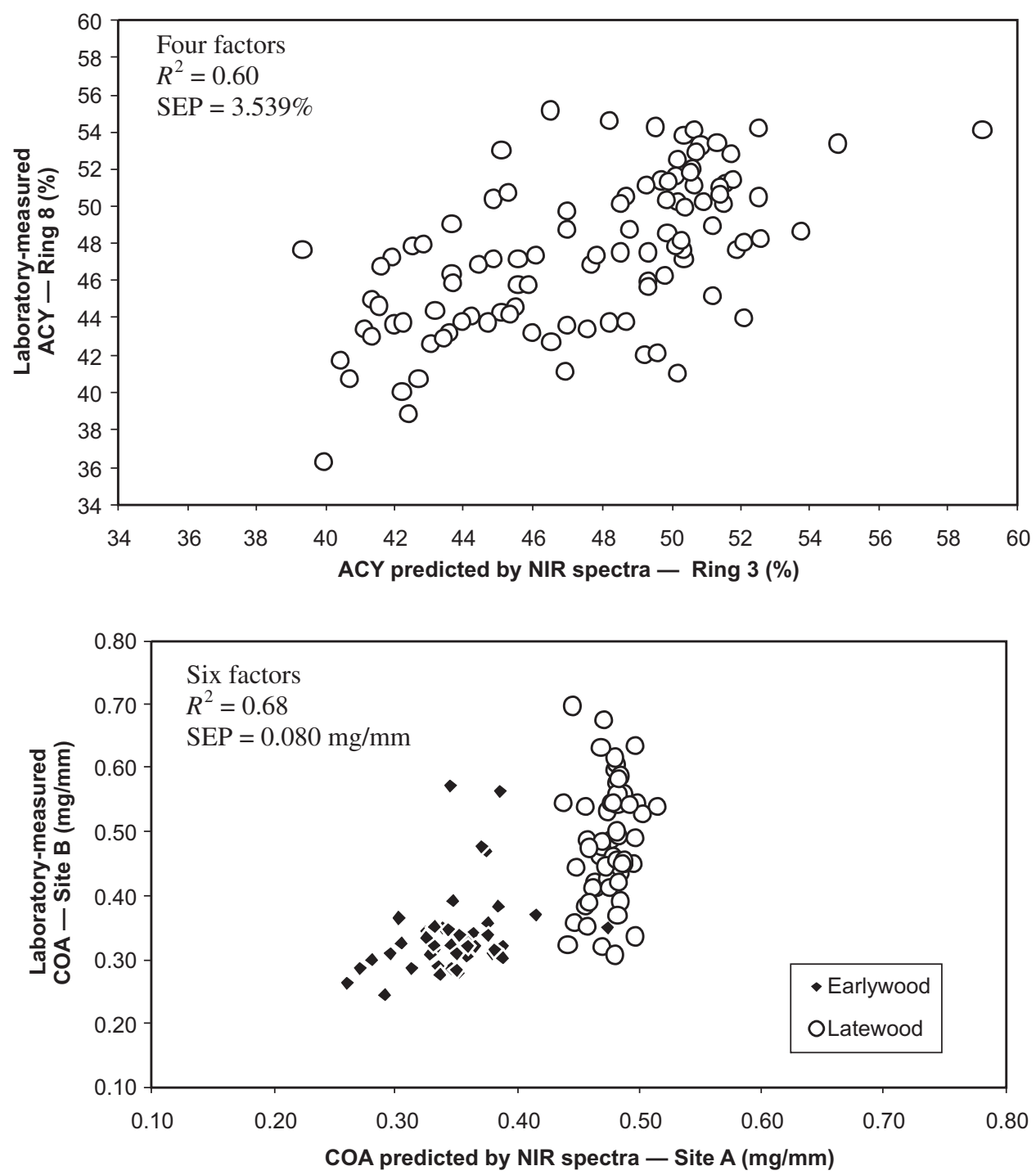

cores $\left(R^{2}=0.81\right)$ for ring 3 earlywood using the Klason lignin method, which had less than half the standard error $(\mathrm{SE}=0.30 \%)$ (Yeh et al. 2004) of the acetyl bromide method used in our study (SE $=0.64 \%$; Table 1). Kelly et al. (2004) found slightly lower associations, with a correlation of 0.81 $\left(R^{2}=0.66\right)$ for predicting lignin content using reflectance NIR spectroscopy on ground wood of one ring in loblolly pine. Similar prediction results were obtained in this study $\left(R^{2}=\right.$ 0.83 ) when the data set was restricted to site A and ring 3 earlywood (data not shown). Thus, it seemed that prediction of lignin content using NIR transmittance could be promising, but accuracy in prediction may be depend on the method of lignin determination and the quality of the laboratory data.

The NIR spectra from site A may be used to predict the wood properties $\alpha$-cellulose content and coarseness on site B with a moderate $R^{2}$ value of 0.63 . Although, these $R^{2}$ values were lower than those for the individual site predictions, they may be sufficient for screening a large number of progenytest trees for ranking and selection purposes. On the other hand, the model of fiber length from one site may not be re- liable for predicting fiber length on another site, as is shown by the low $R^{2}$ value $(0.43)$ and high $\operatorname{SEP}(0.48 \mathrm{~mm})$.

Predictions between ring 3 and ring 8 were moderate for $\alpha$-cellulose content $\left(R^{2}=0.60\right)$ and coarseness $\left(R^{2}=0.68\right)$. Ring 3 calibration equations explained $60 \%$ of the variation in equations for ring $8 \alpha$-cellulose content. Similarly, $68 \%$ of the variation in ring 8 coarseness was explained by ring 3 equations. The moderate $R^{2}$ values for $\alpha$-cellulose content and coarseness indicated that NIR spectra may be used for early selection in wood properties. However, before these NIRspectroscopy prediction models can be used in a breeding program, more wood samples must be sampled to validate the predictions. More sites in different environments need to be sampled to examine environmental effects and estimate the genotype by environment interaction.

\section{Acknowledgements}

This study was supported by a grant from the Department of Energy (DE-FC36-01GO10624), a grant from the US De- 
partment of Agriculture Initiative for Future Agriculture and Food Systems (No. 2001-52104-11224), the North Carolina State University-Industry Cooperative Tree Improvement Program, and the North Carolina Agricultural Research Service. We thank Dr. Laurence Schimleck and Ting-feng Yeh for useful discussion on NIR-related topics and Bambang Hartono and Kevin Copeland for countless hours of wetchemistry work.

\section{References}

Bailleres, H., Davrieus, F., and Ham-Pichavant, F. 2002. Near infrared analysis as a tool for rapid screening of some major wood characteristics in a eucalyptus breeding program. Ann. For. Sci. 59: 479-490.

Barton, F.E., II. 1989. Spectra. In Near infrared reflectance spectroscopy (NIRS): analysis of forage quality. Edited by G.C. Marten, J.S. Shenk, and F.E. Barton II. U.S. Dep. Agric. Agric. Handb. 643. pp. 30-32.

duPlooy, A.B.J. 1980. The relationship between wood and pulp properties of E. grandis (Hill ex-Maiden) grown in South Africa. Appita J. 33: 257-264.

FOSS NIRSystems Inc. 2001. Manual for VISION $^{\circledR}$ software. FOSS NIRSystems Inc., Silver Spring, Md.

Jones, P.D., Schimleck, L.R., Peter, G.F., Daniels, R.F., and Clark, A., III. 2005. Nondestructive estimation of Pinus taeda L. wood properties for samples from a wide range of sites in Georgia. Can. J. For. Res. 35: 85-92.

Kelly, S., Rials, T., Snell, R., Groom, L., and Sluiter, A. 2004. Use of near infrared spectroscopy to measure the chemical and mechanical properties of solid wood. Wood Sci. Technol. 38: 257-276.

Kerekes, R.J., and Schell, C.J. 1995. Effects of fiber length and coarseness on pulp flocculation. TAPPI J. 78(2): 133-139.

Kube, P., and Raymond, C. 2002. Prediction of whole-tree basic density and pulp yield using wood core samples in Euclalyptus nitens. Appita J. 55(1): 43-48.

Li, B., McKeand, S., and Weir, R. 1999. Tree improvement and sustainable forestry - impact of two cycles of loblolly pine breeding in the U.S.A. For. Genet. 6(4): 229-234.

Mark, H., and Workman, J. 1991. Statistics in spectroscopy. Academic Press, San Diego, Calif.

Michell, A.J. 1995. Pulpwood quality estimation by near-infrared spectroscopic measurements on eucalypt woods. Appita J. 48(6): 425-428.

Michell, A.J., and Schimleck L.R. 1996. NIR spectroscopy of woods from Eucalyptus globules. Appita J. 49(1): 23-26.

Miller, C.E. 1989. Analysis of synthetic polymers by near-infrared spectroscopy. Ph.D. thesis, University of Washington, Seattle, Wash.

Myers, G.D. 2001. Thermomechanical pulping of loblolly pine juvenile wood. Wood Fiber Sci. 34(1): 108-115.

Næs, T., Isaksson, T., and Kowalski, B.R. 1990. Locally weighted regression and scatter correction for near-infrared reflectance data. Anal. Chem. 62: 664-673.

Raymond, C.A., and Schimleck, L.R. 2002. Development of near infrared reflectance analysis calibrations for estimating genetic parameters for cellulose content in Eucalyptus globulus. Can. J. For. Res. 32: 170-176.
Raymond, C.A., Schimleck, L.R., Muneri, A., and Michell, A.J. 2001a. Genetic parameters and genotype-by-environment interactions for pulp yield predicted using near infrared reflectance analysis and pulp productivity in Eucalyptus globulus. For. Genet. 8(3): 213-224.

Raymond, C.A., Schimleck, L.R., Muneri, A., and Michell, A.J. $2001 b$. Nondestructive sampling of Eucalyptus globulus and E. nitens for wood properties. III. Predicted pulp yield using near infrared reflectance analysis. Wood Sci. Technol. 35(3): 203-215.

Schimleck, L.R., and Evans, R. 2002. Estimation of wood stiffness of increment cores by near infrared spectroscopy: the development and application of calibrations based on selected cores. IAWA J. 23(3): 217-224.

Schimleck, L.R., and Evans, R. 2003. Estimation of air-dry density of increment cores by near infra-red spectroscopy. Appita J. 56(4): 312-317.

Schimleck, L.R., and Michell, A.J. 1998. Determination of withintree variation of kraft pulp yield using near-infrared spectroscopy. TAPPI J. 81(5): 229-236.

Schimleck, L.R., Michell, A.J., Raymond, C.A., and Muneri, A. 1999. Estimation of basic density of Eucalyptus globulus using near-infrared spectroscopy. Can. J. For. Res. 29: 194-201.

Schimleck, L.R., Evans, R., and Ilic, J. 2001. Estimation of Eucalyptus delegatensis wood properties by near infrared spectroscopy. Can. J. For. Res. 31: 1671-1675.

Schimleck, L.R., Mora, C., and Daniels, R.F. 2003. Estimation of the physical properties of green Pinus taeda radial samples by near infrared spectroscopy. Can. J. For. Res. 33: 2297-2305.

Schimleck, L.R., Kube, P.D., and Raymond, C.A. 2004. Genetic improvement of kraft pulp yield in Eucalyptus nitens using cellulose content determined by near infrared spectroscopy. Can. J. For. Res. 34: 2371-2381.

Sykes, R.W., Isik, F., Li, B., Kadla, J., and Chang, H.-m. 2003. Genetic variation of juvenile wood properties in a loblolly pine progeny test. TAPPI J. 2(12): 3-8.

Thosar, S.S., Forbess, R.A., Ebube, N.K., Chen, Y.X., Rubinovitz, R.L., Kemper, M.S. et al. 2001. A comparison of reflectance and transmittance near-infrared spectroscopic techniques in determining drug content in intact tablets. Pharm. Dev. Technol. 6(1): $19-29$.

Wallis, A.F.A., Wearne, R.H., and Wright, P.J. 1996a. Chemical analysis of polysaccharides in plantation eucalypt woods and pulps. Appita J. 49: 258-262.

Wallis, A. F.A., Wearne, R.H., and Wright, P.J. 1996b. Analytical characteristics of plantation eucalypt woods relating to kraft pulp yields. Appita J. 49: 427-432.

Workman, J.J., Jr. 1992. NIR spectroscopy calibration basics. In Handbook of near-infrared analysis. Edited by D.A. Burns and E.W. Ciurczak. Marcel Dekker, Inc., New York. pp. 274-276.

Wright, J.A., Birkett, M.D., and Gambino, J.T. 1990. Prediction of pulp yield and cellulose content from wood samples using near infrared reflectance spectroscopy. TAPPI J. 73(8): 164-166.

Yeh, T.-f., Chang, H.-m., and Kadla, J.F. 2004. Rapid prediction of solid wood lignin content using transmittance near infrared spectroscopy. J. Agric. Food Chem. 52: 1427-1434.

Yokoyama, T., Kadla, J.F., and Chang, H.-M. 2002. Microanalytical method for the characterization of fiber components and morphology of woody plants. J. Agric. Food Chem. 50: 1040-1044.

Zobel, B.J., and Talbert, J. 1984. Applied forest tree improvement. John Wiley \& Sons, New York. 